\section{Check for updates}

Cite this: Nanoscale, 2021, 13, 261

\title{
Substrate adhesion evolves non-monotonically with processing time in millimeter-scale aligned carbon nanotube arrays $\uparrow$
}

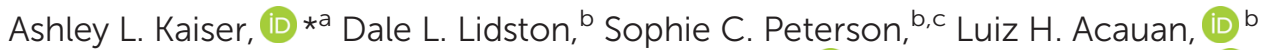 \\ Stephen A. Steiner III, Roberto Guzman de Villoria, (D) $\ddagger^{\mathrm{b}}$ Amy R. Vanderhout, (D) ${ }^{\mathrm{b}}$ \\ Itai Y. Stein (D) $* \S^{b}$ and Brian L. Wardle (D) *b,c
}

\begin{abstract}
The advantageous intrinsic and scale-dependent properties of aligned nanofibers (NFs) and their assembly into 3D architectures motivate their use as dry adhesives and shape-engineerable materials. While controlling NF-substrate adhesion is critical for scaled manufacturing and application-specific performance, current understanding of how this property evolves with processing conditions is limited. In this report, we introduce substrate adhesion predictive capabilities by using an exemplary array of NFs, aligned carbon nanotubes (CNTs), studied as a function of their processing. Substrate adhesion is found to scale non-monotonically with process time in a hydrocarbon environment and is investigated via the tensile pull-off of mm-scale CNT arrays from their growth substrate. CNT synthesis follows two regimes: Mode I ('Growth') and Mode II ('Post-Growth'), separated by growth termination. Within 10 minutes of postgrowth, experiments and modeling indicate an order-of-magnitude increase in CNT array-substrate adhesion strength ( 40 to $285 \mathrm{kPa}$ ) and effective elastic array modulus ( 6 to $47 \mathrm{MPa}$ ), and a two-ordersof-magnitude increase in the single CNT-substrate adhesion force $(\sim 0.190$ to $12.3 \mathrm{nN})$ and work of adhesion ( 0.07 to $1.5 \mathrm{~J} \mathrm{~m}^{-2}$ ), where the iron catalyst is found to remain on the substrate. Growth number decay in Mode I and carbon accumulation in Mode II contribute to the mechanical response, which may imply a change in the deformation mechanism. Predictive capabilities of the model are assessed for previously studied NF arrays, suggesting that the current framework can enable the future design and manufacture of high-value NF array applications.
\end{abstract}

Received 22nd July 2020, Accepted 24th November 2020

DOI: $10.1039 /$ dOnr05469k

rsc.li/nanoscale
Recent progress towards the development of one-dimensional nanoscale systems, such as aligned nanofibers (NFs), nanotubes, and nanowires, ${ }^{1-3}$ provides key opportunities for the design and manufacture of high-performance nano-engineered architectures and devices. ${ }^{4-6}$ In particular, the advantageous intrinsic, scale-dependent, and mass-specific thermal, electrical, and mechanical properties of aligned carbon nanotubes (CNTs) $)^{7-10}$ make these materials promising for commercial applications where robust and tunable interfacial performance is essential. Controlling the adhesion strength of a vertically aligned CNT array to its growth substrate $\left(\sigma_{\mathrm{a}-\mathrm{s}}\right)$ is therefore necessary for shape-engineerable CNT array manufacturing and application-specific performance. ${ }^{7,11,12}$ Tailoring adhesion strength both up and down is important; for example, CNT-based field emitters require large $\sigma_{\mathrm{a}-\mathrm{s}}$ to remain adhered to the substrate during operation, ${ }^{11,13,14}$ and high quality CNT yarns and sheets made from CNT arrays benefit from small $\sigma_{\mathrm{a}-\mathrm{s}}$, as their fabrication often requires facile CNT spinnability from the growth substrate. ${ }^{7,15}$ Other NF systems requiring tunable adhesion strength include $\mathrm{NF}$ arrays for 
gecko-inspired fibrillar adhesives and MEMS devices, ${ }^{16,17}$ contact printing, ${ }^{18-20}$ energy harvesting and storage, ${ }^{4,21,22}$ and thermal interface materials. ${ }^{7,23}$ Models that can guide NF processing towards these applications are a clear gap in the current understanding.

Issues in CNT synthesis are often marked by a limited knowledge of how $\sigma_{\mathrm{a}-\mathrm{s}}$ scales with processing parameters, such as the CNT process time $\left(t_{\mathrm{p}}\right)$ during chemical vapor deposition (CVD), an easily controllable and critical parameter governing array properties ${ }^{24,25}$ such as (primarily) CNT array height $(h)$ tied to the CNT radius and wall thickness (see Fig. 1). This can make the fabrication of multi-scale CNT arrays with tunable adhesion strength challenging when a specific $\sigma_{\mathrm{a}-\mathrm{s}}$ is required, particularly in continuous manufacturing, where the residence time of CNTs in the reactor affects both $h$ and $\sigma_{\mathrm{a}-\mathrm{s}^{\cdot}}{ }^{1,26}$ To address these challenges and expand opportunities for shapeengineerable NF patterning and applications, ${ }^{12,27}$ it is necessary to develop an experimentally validated analytical model that can accurately describe and predict $\sigma_{\mathrm{a}-\mathrm{s}}$ based on $t_{\mathrm{p}}$ while considering the evolving array morphology, CNT-substrate interface, and mechanical behavior based on growth parameters. In this work, $\sigma_{\mathrm{a}-\mathrm{s}}$ is quantified via tensile testing and modeled via contact mechanics, and we find that the nonmonotonic evolution of $\sigma_{\mathrm{a}-\mathrm{s}}$ with $t_{\mathrm{p}}$, particularly post-growth, is driven by the bimodal scaling of CNT geometry, CNT root density (i.e. number density, $n$ ), effective elastic array modulus $(E)$, and interfacial work of adhesion $(\gamma)$ for the CNT-substrate interface.

Due to the importance of $t_{\mathrm{p}}$ in governing process-structureproperty relations, many previous studies ${ }^{24,39-41}$ have evaluated CNT growth as a function of $t_{\mathrm{p}}$ and noted that CNT synthesis follows two modes after growth initiation: Mode I, 'Growth', and Mode II, 'Post-Growth'. These are separated by growth termination, which is preceded by CNT root density decay in Mode I, and is followed (post-termination) by a plateau in $h$ and carbon deposition onto the array in Mode II (see Fig. 1a). ${ }^{24,39-41}$ To link the effects of $t_{\mathrm{p}}$ with ongoing efforts to understand the origins of CNT adhesion, Fig. 1c and d show the results of prior studies that quantified, for a variety of CNT systems and $t_{\mathrm{p}}$ values, the individual CNT-substrate adhesion force $\left(F_{\mathrm{f}-\mathrm{s}}\right)$ via single CNT pull-off/lift-off, ${ }^{28-32}$ the CNT-CNT adhesion force, ${ }^{33-37}$ and $\sigma_{\mathrm{a}-\mathrm{s}}$, which was measured by the pulloff of vertically aligned CNT arrays from their growth substrates. $^{28,29,32,38}$ Fig. 1c shows that these CNT adhesion forces vary only over two orders of magnitude. Along with $\sigma_{\mathrm{a}-\mathrm{s}}$ shown in Fig. 1d, different adhesion values can be achieved due to the unique CNT sizes, number densities, moduli, and work of adhesion values that result from each study's CVD growth conditions and catalysts. Our work with a single system covers this entire range of CNT adhesion forces just from varying $t_{\mathrm{p}}$. Unfortunately, predictive scaling relations for $F_{\mathrm{f}-\mathrm{s}}$ and $\sigma_{\mathrm{a}-\mathrm{s}}$ do not yet exist, and these are needed to quantify the substrate adhesion and $\gamma$ evolution of both individual CNTs and arrays containing $\sim 10^{9}-10^{11}$ aligned CNTs, ${ }^{7,42}$ which are commonly used in applications. Therefore, to address this gap, we present an experimentally validated model and mecha-

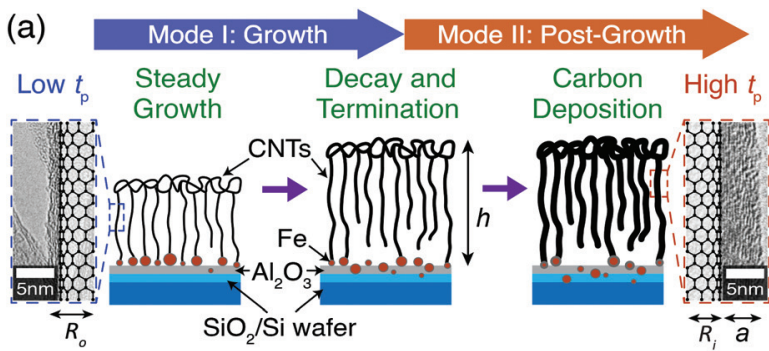

(b) Growth and Post-Growth Mechanisms of Adhesion

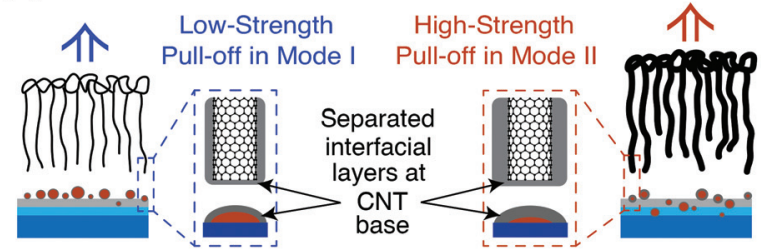

(c) CNT-Substrate Adhesion CNT-CNT Adhesion
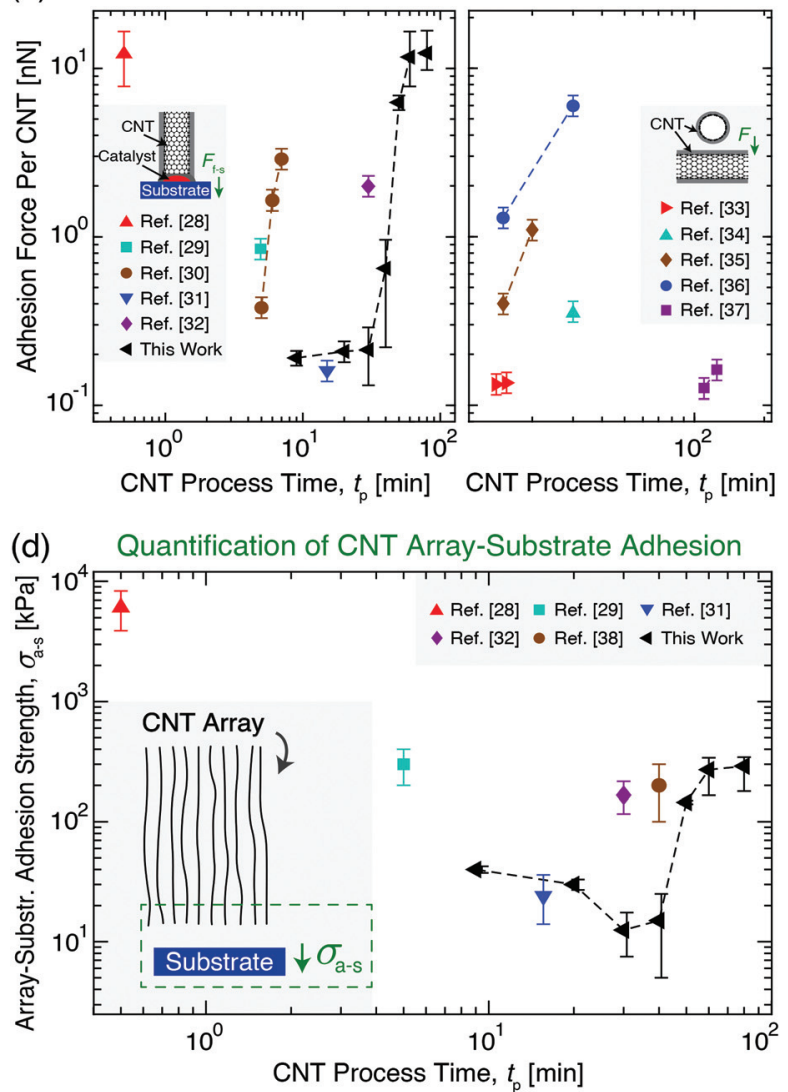

Fig. 1 Overview of vertically aligned multiwall carbon nanotube (CNT) array growth and CNT adhesion to a Si wafer growth substrate with an Fe catalyst layer. (a) Illustration and transmission electron microscopy images showing CNT array evolution after growth initiation through two Modes as a function of CNT process time $\left(t_{\mathrm{p}}\right)$ : Mode I ('Growth') and Mode II ('Post-Growth'), separated by CNT root density decay towards growth termination and a plateau in array height $(h)$ at the end of Mode I. Carbon deposition in Mode II increases CNT wall thickness (a) and outer radius $\left(R_{\mathrm{o}}\right)$ at constant inner radius $\left(R_{\mathrm{i}}\right)$, increasing (b) CNT-substrate adhesion (i.e. ultimate tensile stress) measured via tensile pull-off. Illustrations and plots show previously reported (c) adhesion force $(F)$ between a vertical CNT and its growth substrate $\left(F_{\mathrm{f}-\mathrm{s}}\right)^{28-32}$ and between two CNTs ${ }^{33-37}$ and (d) CNT array-substrate adhesion strength $\left(\sigma_{a-s}\right)$ between the array and its growth substrate $28,29,31,32,38$ as a function of $t_{\mathrm{p}}$. 
nisms to describe adhesion at the CNT-substrate interface. Several of the interfacial effects, array mechanics, and physiochemical mechanisms that could be responsible for the origin of non-monotonic $\sigma_{\mathrm{a}-\mathrm{s}}$ scaling with $t_{\mathrm{p}}$ are discussed, and future studies to support the manufacturing of NF systems with predictable and application-specific substrate interactions are proposed.

\section{Results}

\section{Nanofiber-substrate adhesion theoretical framework}

To provide mechanistic insight into the origin and scaling of $\sigma_{\mathrm{a}-\mathrm{s}}, E$, and $\gamma$ with processing, a model is developed based on the following assumptions (see derivation in section S1 of the ESI $\dagger$ ). The bulk NF array, here an exemplary CNT array as shown in Fig. 2a, is composed of vertically aligned, hollow, and cylindrical multiwall CNTs, where CNT-CNT interactions $^{43-45}$ and waviness effects ${ }^{42,46}$ are implicitly captured by the volume-averaged effective elastic array modulus $E$, and only the annular CNT bases contact the growth substrate (Fe catalyst particles on an $\mathrm{Al}_{2} \mathrm{O}_{3} / \mathrm{SiO}_{2} / \mathrm{Si}$ wafer). Fig. 2a shows that the CNT-substrate contact area is between $n$ annular CNT bases and the CNT-catalyst growth front interface, following hollow cylinder geometry. ${ }^{47,48}$ The CNT-substrate interaction is assumed to occur via dispersive adhesion attraction based on the intermolecular van der Waals (VDW) forces acting between the contacting materials, ${ }^{49-51}$ where each CNT has its own adhesion force $\left(F_{\mathrm{f}-\mathrm{s}}\right) \cdot \sigma_{\mathrm{a}-\mathrm{s}}$ (i.e. the array mean ultimate tensile stress) is derived based on the Johnson-KendallRoberts (JKR) contact mechanics theory for relatively compliant elastic solids, ${ }^{49,50,52}$ where $\sigma_{\mathrm{a}-\mathrm{s}}$ represents the detachment of all CNT bases from the substrate via the minimization of elastic and surface energy, assuming no energy dissipation outside of the separation region following previous work for similar fibrillar systems. ${ }^{52-55} \gamma$ is assumed to be constant within each mode and signifies twice the surface free energy of the contacting surfaces in Kendall's framework. ${ }^{28,50,56,57}$

Here, we consider the CNT array-substrate adhesion strength $\left(\sigma_{\mathrm{a}-\mathrm{s}}\right)$ to be $F_{\mathrm{f}-\mathrm{s}}$ scaled by $n$, where $\sigma_{\mathrm{a}-\mathrm{s}}\left(t_{\mathrm{p}}\right)$ can be calculated via eqn (1) (see Fig. 2b for experiment-model agreement of previously reported vertically aligned CNT and polymer NF arrays). The prefactor $\beta \sim 0.4$ accounts for variations in the contact region, ${ }^{48}$ such as geometric irregularities, defects, and surface roughness reducing the true contact area in fibrillar systems. ${ }^{57,63,64} F_{\mathrm{f}-\mathrm{s}}\left(t_{\mathrm{p}}\right)$ is then estimated via eqn (2) (see Fig. 2c), where synchronous CNT separation from the substrate is assumed for simplicity, and failure occurs at a deterministic mean stress ${ }^{28,29,52}$ based on bulk adhesion scaling with the number of contacts, ${ }^{65}$ such as for gecko-inspired microfibrillar dry adhesives ${ }^{20,47,52}$ and recently for micron-tall vertically aligned CNT arrays. ${ }^{28,29}$ Finally, linear elastic behavior for the CNT array is assumed during tensile pull-off testing, ${ }^{29,42}$ with increases in $E$ proportional to the increasing adhesion force and CNT outer radius $\left(R_{\mathrm{o}}\right)$ at a constant CNT inner radius $\left(R_{\mathrm{i}}\right)$ with $t_{\mathrm{p}}$. Shear/lateral adhesion force contributions from CNT
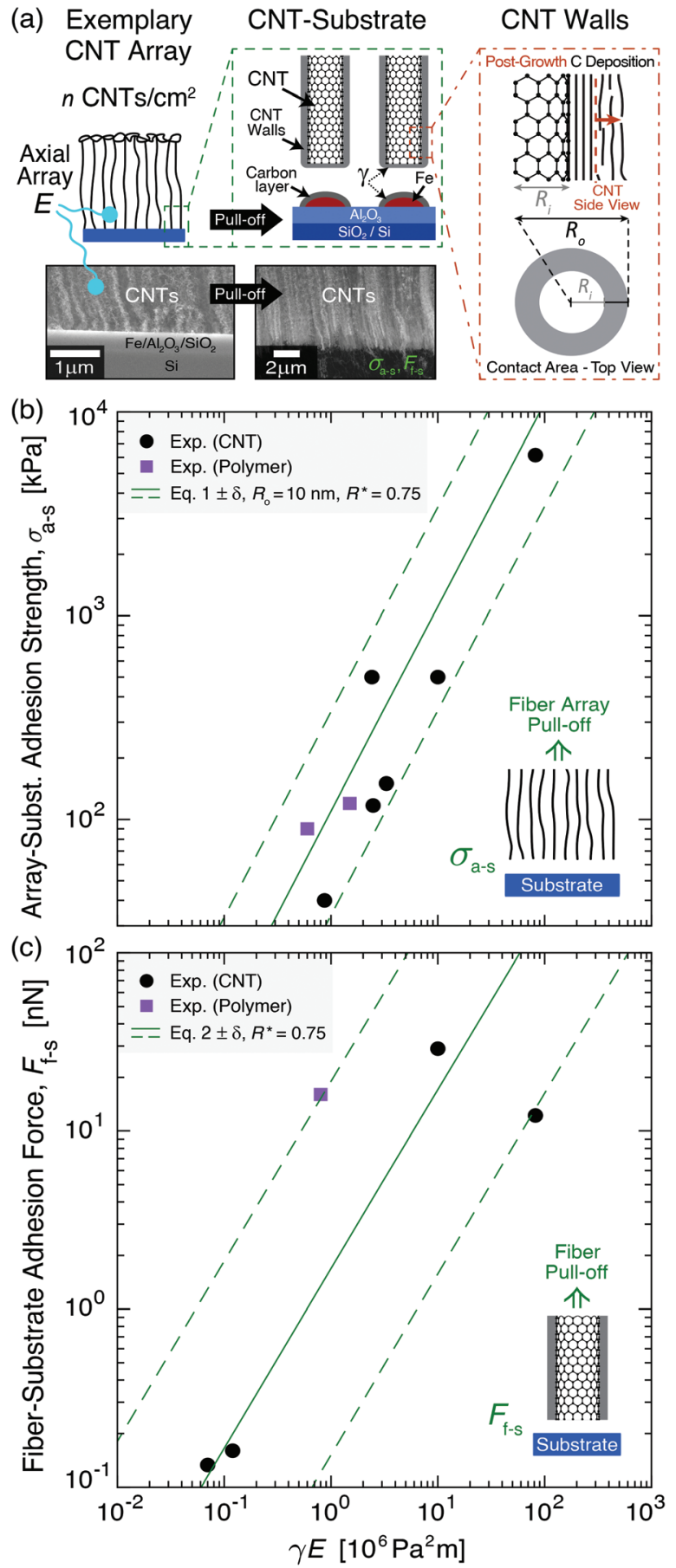

Fig. 2 System geometry and corresponding adhesion modeling applied to previously reported experimental results of bulk fiber array-substrate adhesion strength $\left(\sigma_{\mathrm{a}-\mathrm{s}}\right)$ and single fiber-substrate adhesion force $\left(F_{\mathrm{f}-\mathrm{s}}\right)$. Adhesion is plotted versus the product of the work of adhesion between the separating fiber-substrate interfaces $(\gamma)$ and the effective elastic array modulus $(E)$ in eqn (1). (a) Illustrations and scanning electron microscopy images of an exemplary CNT array showing its tensile pull-off from the growth substrate and adhesion modeled via hollow cylinder geometry. (b) $\sigma_{\mathrm{a}-\mathrm{s}}$ versus $\gamma E$ showing experiment-model agreement (eqn (1)) for $R_{\circ}=10 \mathrm{~nm}, R^{\star}=\left(R_{\circ}{ }^{2}-R_{\mathrm{i}}{ }^{2}\right) / R_{\circ}{ }^{2}=0.75, n=2 \times 10^{9}-2 \times 10^{10}$ fibers per $\mathrm{cm}^{2}$ (solid line $\rightarrow 6.5 \times 10^{9}$ fibers per $\mathrm{cm}^{2}$ ), and $\beta=0.4$ for aligned $\mathrm{CNT}^{28,38,55,58,59}$ and polymer ${ }^{60,61}$ fiber arrays. (c) $F_{\mathrm{f}-\mathrm{s}}$ versus $\gamma E$ showing experiment-model agreement (eqn (2)) for $R^{\star}=0.75, R_{\circ}=2-50 \mathrm{~nm}$ (solid line $\rightarrow 10 \mathrm{~nm}$ ), and $\beta=0.4$ for aligned $\mathrm{CNT}^{28,31,33,58}$ and polymer ${ }^{62}$ fiber arrays. 
sections lying parallel to the substrate are neglected due to the vertical CNT growth direction during synthesis and minimal compressive preload during testing. ${ }^{64,66}$ Fig. $2 \mathrm{~b}$ and c show the key drivers in this theoretical framework and illustrate the experiment-model agreement for exemplary values of $n, R_{\mathrm{o}}$, and $R^{*}=\left(R_{\mathrm{O}}{ }^{2}-R_{\mathrm{i}}{ }^{2}\right) / R_{\mathrm{O}}{ }^{2}$. These are plotted versus characteristic $\gamma E$ values for CNT and polymer NF systems, representing $0.05 \mathrm{~J}$ $\mathrm{m}^{-2} \lesssim \gamma \lesssim 5 \mathrm{~J} \mathrm{~m}^{-2}$ and $0.2 \mathrm{MPa} \lesssim E \lesssim 200 \mathrm{MPa}$.

$$
\begin{gathered}
\sigma_{\mathrm{a}-\mathrm{s}}=n \beta \sqrt{8 \pi \gamma E\left(R_{\mathrm{o}}^{2}-R_{\mathrm{i}}^{2}\right)^{3 / 2}} \\
F_{\mathrm{f}-\mathrm{s}}=\frac{\sigma_{\mathrm{a}-\mathrm{s}}}{n}
\end{gathered}
$$

\section{CNT-substrate adhesion: experimental and modeling results}

To experimentally quantify $\sigma_{\mathrm{a}-\mathrm{s}}$ as a function of $t_{\mathrm{p}}$ up to $80 \mathrm{~min}$, mm-scale vertically aligned CNT arrays were synthesized via base-growth CVD and are categorized as Mode I: 'Growth', $t_{\mathrm{p}}=9-40 \mathrm{~min}$, and Mode II: 'Post-Growth', $t_{\mathrm{p}}=$ 40-80 min, following abrupt vertical growth termination observed at $40 \mathrm{~min}$ in this system. It is important to note that the process conditions, including the hydrocarbon flow, are part of the post-growth process. CNT arrays were then separated from their $\mathrm{Fe}$ catalyst $/ \mathrm{Al}_{2} \mathrm{O}_{3} / \mathrm{Si}$ wafer substrates via the direct tensile testing procedure illustrated in Fig. 3, after which their structure and morphology were characterized as inputs into the adhesion model (see additional details in Methods and sections S2-S4 in the ESI $\dagger$ ). TEM images of individual CNTs show that $R_{\mathrm{i}}\left(t_{\mathrm{p}}\right)$ remains constant at $\sim 3 \mathrm{~nm}$, while the average wall thickness increases from $\sim 1.5$ to $7.0 \mathrm{~nm}$ for $t_{\mathrm{p}}$ $=9$ to $80 \mathrm{~min}$. The wall thickness is observed to follow a quadratic scaling with $t_{\mathrm{p}}$ due to carbon deposition on the outer CNT walls, which increases the CNT diameter, stiffens the array, and decreases the averaged $\mathrm{sp}^{2}$ carbon character during growth $^{41,67,68}$ and post-growth ${ }^{69-72}$ (Fig. S6-S8†). The number density of CNTs attached to the substrate ( $n$, see Fig. S2 $\dagger$ ) was calculated as $\sim 2.1 \times 10^{10} \mathrm{CNTs}$ per $\mathrm{cm}^{2}$ at the start of Mode I $\left(t_{\mathrm{p}}=9 \mathrm{~min}\right)$ based on the $\sim 1 \%$ CNT volume fraction $\left(V_{\mathrm{f}}\right)$ for a $\sim 1$ mm-tall CNT array. ${ }^{73-75}$

In adhesion testing, the CNT array-substrate sample is glued to two scanning electron microscopy (SEM) stubs and pulled upwards until full wafer detachment from the array. This mechanical test is well-suited to the vertically aligned CNT array morphology ${ }^{28,29,76}$ to accurately measure the CNTsubstrate adhesion force, $F_{\mathrm{a}-\mathrm{s}}$, defined as the maximum tensile force necessary to separate the two array-substrate interfaces. ${ }^{76}$ This gives $\sigma_{\mathrm{a}-\mathrm{s}}$, the array mean ultimate tensile stress, representing the CNT-substrate adhesion strength. For each measured strain, $\sigma$ is obtained by dividing $F$ by the apparent CNT array area, $A_{\text {array }} \sim 1 \mathrm{~cm}^{2}$. Representative stress-strain curves are plotted for the range of tested $t_{\mathrm{p}}$ values shown in Fig. $3 \mathrm{~b}$, and the average $\sigma_{\mathrm{a}-\mathrm{s}}\left(t_{\mathrm{p}}\right)$ values are plotted in Fig. $4 \mathrm{a} . E$ is measured from the initial linear slope of the stress-strain curves and is observed to increase by nearly $10 \times$ from $\sim 6.14 \pm$ 1.7 MPa in Mode I to $\sim 47.1 \pm 21 \mathrm{MPa}$ in Mode II. (a) Pull-off to measure $\sigma_{\text {a-s }}, F_{\text {t-s }} \quad$ CNT-Substrate
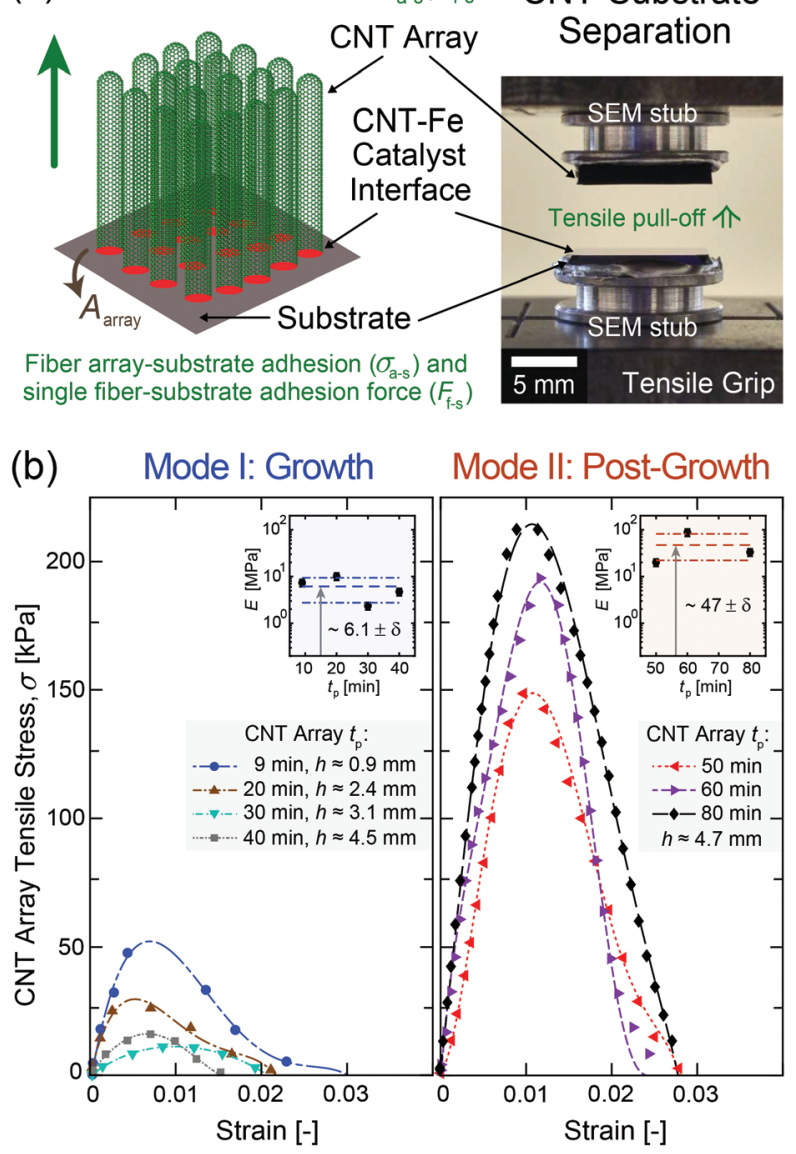

(c) Separated CNT Roots from Substrate-bound Fe:

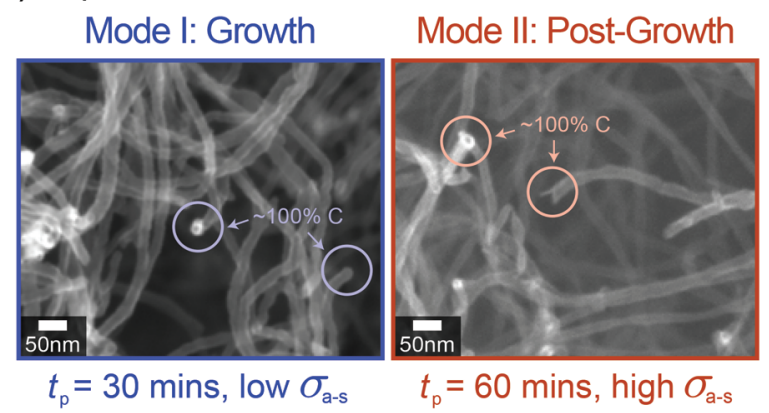

Fig. 3 Experimental setup used to measure CNT array-substrate adhesion $\left(\sigma_{\mathrm{a}-\mathrm{s}}\right)$ and the resulting mechanical and morphological testing results as a function of CNT process time $\left(t_{\mathrm{p}}\right)$. (a) Illustration and optical image showing that $\sigma_{\mathrm{a}-\mathrm{s}}$ is obtained by separating a $\mathrm{mm}$-tall, $\mathrm{cm}$-wide vertically aligned CNT array from its growth substrate $\left(\mathrm{Fe} / \mathrm{Al}_{2} \mathrm{O}_{3} / \mathrm{SiO}_{2} / \mathrm{Si}\right)$ during tensile pull-off testing. (b) Exemplary stress-strain curves and effective elastic array modulus $E$ with standard error $\delta$ (see insets) obtained via tensile testing at each $t_{\mathrm{p}}$ in Mode I ('Growth') and Mode II ('Post-Growth') showing evolution of $\sigma_{\mathrm{a}-\mathrm{s}}$, which is defined as the maximum measured tensile stress, i.e. $F_{\mathrm{a}-\mathrm{s}}$ divided by the apparent array cross-sectional area, $A_{\text {array }} \sim 1 \mathrm{~cm}^{2}$. Polynomial fits (dashed lines) are included as a 'guide to the eye' for the experimental stress-strain data (markers). (c) SEM images showing similar morphologies of open-ended, iron-free CNT roots measured via EDS after their separation from the substrate-bound iron catalyst particles at exemplary Mode I and Mode II $t_{\mathrm{p}}$ values of 30 and $60 \mathrm{~min}$ (low and high $\sigma_{\mathrm{a}-\mathrm{s}}$ ), respectively. 

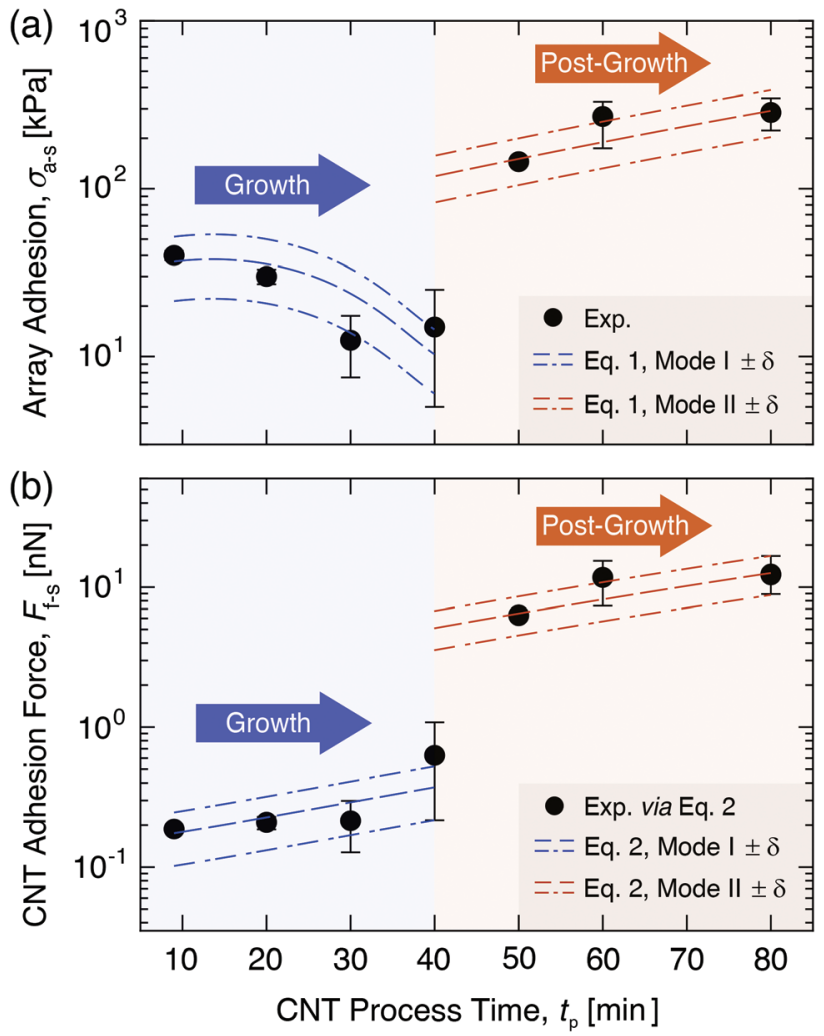

Fig. 4 Experimental quantification and modeling of the CNT arraysubstrate adhesion strength $\left(\sigma_{\mathrm{a}-\mathrm{s}}\right)$ and individual CNT-substrate adhesion force $\left(F_{f-s}\right)$ as a function of CNT process time $\left(t_{p}\right)$ in Mode I ('Growth') and Mode II ('Post-Growth'). (a) Plot showing that the experimental and model-predicted $\sigma_{\mathrm{a}-\mathrm{s}}$ values (eqn (1)) evolve non-monotonically with $t_{\mathrm{p}}$, decreasing in Mode I due to reduced $n$, and increasing in Mode II due to higher $\gamma_{1} E$, and $R_{\mathrm{o}}$ from carbon deposition within the CNT array. Continuity is not enforced at $t_{\mathrm{p}}=\mathbf{4 0} \mathrm{min}$ to show the Mode I to Mode II shift at growth termination, and $\delta$ represents standard error. (b) Plot showing that the experimental and predicted $F_{f-s}$ values (eqn (2)) scale with $t_{\mathrm{p}}$ and increase by an order of magnitude from Mode I to Mode II due to increases in $\gamma, E$, and $R_{\mathrm{o}}$ with $t_{\mathrm{p}}$.

From Fig. 3b and $4 \mathrm{a}, \sigma_{\mathrm{a}-\mathrm{s}}$ scales non-monotonically with $t_{\mathrm{p}}$, decreasing from $40.0 \pm 2.5 \mathrm{kPa}$ at $t_{\mathrm{p}}=9 \mathrm{~min}$ (start of Mode I) to $12.5 \pm 5.0 \mathrm{kPa}$ at $30 \mathrm{~min}$, then $15.0 \pm 5.0 \mathrm{kPa}$ at $40 \mathrm{~min}$ (end of Mode I), and then increases by an order of magnitude to $145 \pm 5.0 \mathrm{kPa}$ at $50 \mathrm{~min}$ (after the onset of Mode II), finally reaching $285 \pm 41 \mathrm{kPa}$ at $80 \mathrm{~min}$. This signifies that the adhesive response is governed by the evolving CNT geometry and total CNT-substrate contact area (via $R_{\mathrm{o}}$ and $n$ ), the array mechanics (via $E$ ), and the work of adhesion between the separating interfaces (via $\gamma$ ) due to the evolving carbon character with increasing $t_{\mathrm{p}}$. Fig. S4† shows SEM images of the wafer surface post-separation at each $t_{\mathrm{p}}$, where the absence of catalyst pits $^{28,41}$ suggests that the iron catalyst particles that nucleated CNTs remained on the substrate after tensile testing. ${ }^{19,77,78}$ Similarly, representative SEM images with energy-dispersive X-ray spectroscopy (EDS) analysis for element mapping in Fig. 3c show open ended, iron-free, and carboncovered CNT roots in the array after separation in both Modes, showing that the CNTs separate from the substrate-bound Fe catalyst particles during pull-off. No iron is found attached to the CNT roots (Fig. S5 and section S2 in the ESI $\dagger$ ), similar to previous work at moderate $t_{\mathrm{p}}{ }^{18,79-82}$ This suggests that the breaking interface is the same for both modes, and is likely between the relatively low surface energy $\mathrm{C}-\mathrm{C}$ layers at the CNT base resulting from carbon accumulation during the CVD process. Therefore, $\sigma_{\mathrm{a}-\mathrm{s}}$ is associated with the separation of the crystalline CNT base from the carbon on the catalyst surface, as shown in Fig. 2a.

With inputs of experimental values of $\sigma_{\mathrm{a}-\mathrm{s}}, R_{\mathrm{o}}, R_{\mathrm{i}}$, and $E$, and estimated values of $\beta$ and $n$, eqn (1) is used to calculate $\gamma$ as a function of $t_{\mathrm{p}}$ to provide theoretical insight into CNT-substrate adhesion. The evolution of $n$ with $t_{\mathrm{p}}$ was estimated as follows for use in eqn (1) and (2). During Mode I for $t_{\mathrm{p}}>$ $9 \mathrm{~min}, n$ is set to follow a cubic decay to reach $\sim 11 \%$ of its original value at growth termination, in agreement with previously reported measurements of $n$ decay to $\sim 11 \%$ of the original $n$ at termination due to CNT-substrate debonding during growth, and the subsequent loss of a self-supporting array structure. ${ }^{40,83}$ Incorporating this scaling into eqn (1) is consistent with the experimental Mode I $E$ values $(\sim 6.14 \pm 1.7 \mathrm{MPa})$ in the expected range of 1-10 MPa based on prior work for similar CVD-grown aligned CNT arrays. ${ }^{30,42,46,84,85}$ In Mode I, significant moduli variations are not expected due to the minimal changes in carbon character. It is noted that this effective array modulus, not the orders-of-magnitude higher intrinsic CNT axial elastic modulus of $1 \mathrm{TPa},{ }^{86}$ governs the bulk CNT array's interfacial behavior, similar to the mechanics governing the capillary densification of CNT arrays, for which CNT-substrate adhesion is an important consideration. ${ }^{27,87,88}$ Mode I $n\left(t_{\mathrm{p}}\right)$ is therefore quantified by a cubic fit, as detailed in section S1 of the ESI. $\dagger$ The $\sim 11 \%$ lower $n$ value at growth termination (calculated as $\sim 2.3 \times 10^{9}$ CNTs per $\mathrm{cm}^{2}$ at $t_{\mathrm{p}}=40 \mathrm{~min}$ ) is kept constant in Mode II, since CNT growth in the vertical direction has stopped, and further information about $n$ scaling after growth termination is not currently available. Quantification of $n$ could be incorporated into this model in future studies. In addition, while we do observe additional growth attempts by several short, small-diameter CNTs in Mode II (Fig. S4 $\dagger$ ), consistent with prior work, these CNTs are not incorporated into the $n$ scaling, since they are not pulled off of the substrate during tensile testing and therefore are not expected to contribute significantly to the bulkscale adhesion response. ${ }^{28}$ Finally, continuity in $\sigma_{\mathrm{a}-\mathrm{s}}, F_{\mathrm{f}-\mathrm{s}}, E$, and $\gamma$ between Mode I and Mode II is not enforced at $t_{\mathrm{p}}=$ 40 min (see Fig. 4), since more data supplemented by stochastic simulations are required to accurately characterize the scaling of this transition. Additional details concerning $\gamma, n$, and $E$ scaling with $t_{\mathrm{p}}$, including all experimentally measured and calculated values, are shown in Table S1 in section S1 of the ESI. $\dagger$

With $n\left(t_{\mathrm{p}}\right)$ established, $\gamma$ is calculated via eqn (1) to be $0.07 \pm 0.02 \mathrm{~J} \mathrm{~m}^{-2}$ in Mode I and $1.5 \pm 0.2 \mathrm{~J} \mathrm{~m}^{-2}$ in Mode II. These average values are then input into eqn (1) and (2) with the average $E$ values, $R_{\mathrm{O}}$ scaling, and $n$ scaling to plot continu- 
ous functions of $\sigma_{\mathrm{a}-\mathrm{s}}\left(t_{\mathrm{p}}\right)$ and $F_{\mathrm{f}-\mathrm{s}}\left(t_{\mathrm{p}}\right)$ in each Mode (Fig. 4). These $\gamma$ values, which equate to surface energies of $\sim 0.033 \mathrm{~J}$ $\mathrm{m}^{-2}$ in Mode I and $\sim 0.75 \mathrm{~J} \mathrm{~m}^{-2}$ in Mode II, are in the range of intermolecular VDW forces for the separation of carbon layers that are proposed to be governing $\sigma_{\mathrm{a}-\mathrm{s}}$ in this system. ${ }^{89-92}$ They are also consistent with previously reported surface energy values of graphitic $\mathrm{C}-\mathrm{C}$ interfaces (i.e. CNTs, graphene, and graphite) in the range of $0.029-0.875 \mathrm{~J} \mathrm{~m}^{-2} \cdot{ }^{66,89,91-96}$ Higher $\gamma$ is attributed to carbon deposition in the array with a higher $\mathrm{sp}^{3}$ carbon character, exhibiting further interactions in addition to the ideal peeling of smooth, well-ordered $\mathrm{sp}^{2}$ graphitic surfaces with correspondingly lower surface energies. $^{54,56,96}$ The calculated $\gamma$ values also support experimental observations, as Raman spectroscopy analysis ${ }^{69,97-99}$ of the CNT base after array pull-off (see section S4 of the ESI $\dagger$ ) shows that the CNTs exhibit a well-ordered, $\mathrm{sp}^{2}$ graphitic wall structure in Mode I, and a more defective, turbostratic $\mathrm{sp}^{3}$ carbon structure in Mode II as carbon deposits on the outer CNT walls at long $t_{\mathrm{p} \cdot}{ }^{100}$ Since the wafer surface (Fig. S4 $\dagger$ ) is expected to have a broader distribution of carbon character as compared to the CNT roots (i.e. having carbon that encapsulates the activated catalysts, covers larger iron particles and the alumina surface, and comprises residual short CNTs), ${ }^{40,76,83}$ analysis of the CNT array roots after pull-off can provide more instructive characterization of the deposited carbon that gives rise to the adhesion evolution. Therefore, increases in $\sigma_{\mathrm{a}-\mathrm{s}}$ in Mode II are likely attributed to higher $R_{\mathrm{o}}, E$, and $\gamma$ based on the $\mathrm{sp}^{2}$-to-sp ${ }^{3}$-dominated carbon evolution and deposition with $t_{\mathrm{p}},{ }^{54,56,96}$ where significant changes in $E$ and $\gamma$ may be especially responsible for the rapid adhesion evolution following growth termination. In sum, the application of this adhesion model to our aligned CNT arrays shows that $\sigma_{\mathrm{a}-\mathrm{s}}$ evolves non-monotonically with $t_{\mathrm{p}}$ and increases by an order of magnitude after growth termination, which is attributed to $n$ decay during growth and a subsequent order-of-magnitude increase in $E$ and $\gamma$ due to carbon deposition in Mode II.

\section{Discussion}

\section{Mechanistic insights into CNT-substrate adhesion}

The CNT-substrate adhesion model is used to predict $\gamma, \sigma_{\mathrm{a}-\mathrm{s}}$, and $F_{\mathrm{f}-\mathrm{s}}$, which corroborates experimental results of iron-free CNT roots and C-C layer separation during CNT array pull-off. Since $\gamma$ for CNTs with VDW-dominated adhesion is approximately constant for CNTs with more than 3 walls, ${ }^{101}$ and $\gamma$ is assumed to be higher in Mode II only due to the increased turbostratic/disordered carbon character, $\gamma$ is kept constant throughout Mode I and Mode II to represent the VDW-dominated CNT-C layer interaction as the weakest interface governing CNT-substrate separation. This carbon layer may form during the cooling process due to carbon precipitation from the iron catalyst, ${ }^{81,102,103}$ and it may also increase in thickness after growth termination due to catalyst deactivation ${ }^{39,104,105}$ and deposition of additional carbon during Mode II. Furthermore, since the interaction energy between $\mathrm{C}-\mathrm{Fe}$ is higher (yielding $\gamma \sim 1.84 \mathrm{~J} \mathrm{~m}^{-2}$ or greater) ${ }^{19,39,106,107}$ and this is inconsistent with our $\sigma_{\mathrm{a}-\mathrm{s}}$ and $\gamma$ calculations, it is proposed that the separated carbon layer at the CNT root remains on the Fe catalyst after CNT pull-off. ${ }^{108}$ Still higher are the $\mathrm{Fe}-$ alumina interaction energies ${ }^{19,82}$ as well as iron oxide $\mathrm{e}^{109,110}$ and iron carbide, ${ }^{111,112}$ which would all yield $\gamma>2 \mathrm{~J} \mathrm{~m}^{-2}$, exceeding the $\gamma$ values here of 0.07 and $1.5 \mathrm{~J} \mathrm{~m}^{-2}$ in Mode I and Mode II, respectively. Therefore, in contrast to previous work at short $t_{\mathrm{p}}$ (on the order of seconds, where the Fe catalyst was observed to stay attached to the CNT roots during the tensile pull-off of a microscale CNT array), ${ }^{28}$ only the $\mathrm{C}-\mathrm{C}$ interfaces are observed to separate in this system at moderate to long $t_{\mathrm{p}}$, yielding a maximum $\sigma_{\mathrm{a}-\mathrm{s}}$ of $\sim 285 \mathrm{kPa}$ after $80 \mathrm{~min}$ of processing. Based on these results, it is plausible that additional increases in $\sigma_{\mathrm{a}-\mathrm{s}}$ may be obtained via extended carbon deposition at longer $t_{\mathrm{p}}$ to further engineer the substrate adhesion strength of aligned NF arrays.

Next, the mechanisms governing CNT array deformation and substrate adhesion are investigated as a function of $t_{\mathrm{p}}$. Comparing the average experimental $E$ values for Mode I and Mode II (6.14 $\pm 1.7 \mathrm{MPa}$ and $47.1 \pm 21 \mathrm{MPa}$, respectively) to the mechanical properties of carbon systems reveals a connection to two elastic constants for carbon materials: $\mathrm{C}_{44} \approx 0.35 \mathrm{GPa}$ for turbostratic graphite, the inter-layer shear modulus, ${ }^{113}$ and $\mathrm{C}_{33} \approx 37 \mathrm{GPa}$, the inter-layer cleavage modulus. ${ }^{113}$ These $E$ values can be obtained by scaling the two governing elastic constants by the CNT $V_{\mathrm{f}}$ (here 1 vol\%), since CNT arrays are nanoporous materials, and the elastic axial moduli in selfassembled nanoporous films can exhibit a linear, foam-like scaling with density due to two-dimensional effects. ${ }^{45,46}$ Therefore, $E$ in Mode I and Mode II can be estimated as 1\% of $0.35 \mathrm{GPa}\left(\mathrm{C}_{44}\right)$ and $37 \mathrm{GPa}\left(\mathrm{C}_{33}\right)$, with an additional reduction of $\mathrm{C}_{33}$ by $11 \%$ due to reduced $n$ and effective stiffness at growth termination for Mode II. This yields $\sim 3.5 \mathrm{MPa}$ for Mode I and $41 \mathrm{MPa}$ for Mode II, which matches closely with experimental values and prior work obtaining CNT array moduli in the MPa range. ${ }^{27,42,45,113}$ Therefore, it is proposed that in the transition from Mode I to Mode II, carbon deposition in the array (i.e. carbon deposited conformally onto the CNTs in the array) causes a change in deformation mechanism from $\mathrm{C}_{44}$ to $\mathrm{C}_{33}$, consistent with the directionally dependent elastic constants of turbostratic graphitic crystallites and the relative importance of $\mathrm{C}_{33}$ as the bending stiffness of an individual CNT, which increases nonlinearly $\left(R^{4}\right)$ by the carbon deposition versus a linear increase for $\mathrm{C}_{44}$. To support this trend, $E$ has previously been observed to scale with NF diameter, ${ }^{79}$ the number of CNT walls and contact area, ${ }^{40,114}$ carbon deposition on the array, ${ }^{45}$ and CNT $V_{\mathrm{f} \cdot} \cdot{ }^{42,45,114,115}$

\section{Applicability to previously reported CNT-substrate adhesion}

Modeling results that are developed and experimentally-validated here are compared to past work to assess the model's consistency with previously characterized CNT arrays. Fig. 1c shows that CNT-CNT and CNT-substrate adhesion forces versus $t_{\mathrm{p}}$ are of similar magnitude, showing that the weakest interface between CNTs and their growth substrate can be 
between the CNT roots and the carbon layer as observed here, which has not previously been modeled at the bulk scale. This result agrees with our experiments, modeling, and prior experimental evidence that Fe particles can remain on the substrate after CNT array separation, ${ }^{79,80,108}$ as measured via SEM and X-ray photoelectron spectroscopy for aligned CNT arrays. $^{18,81,82}$ Specifically, previously reported $F_{\mathrm{f}-\mathrm{s}}$ values of $\sim 0.133-0.28 \mathrm{nN}^{31,33,65,79}$ are in the same range as the calculated results of $\sim 0.204 \pm 0.007 \mathrm{nN}$ on average in Mode I (before growth termination), as well as at the start of Mode I: $\sim 0.190 \pm$ $0.011 \mathrm{nN}$ for a $\sim 1 \mathrm{~mm}$-tall CNT array $\left(t_{\mathrm{p}} \approx 9 \mathrm{~min}, \sim 9 \mathrm{~nm}\right.$ outer CNT diameter, and 3-7 CNT walls). This agrees closely with the force output of $F_{\mathrm{f}-\mathrm{s}} \sim 0.16 \mathrm{nN}$ presented in ref. 31 for CNTs having an outer diameter of $9 \mathrm{~nm}$ and 5 walls. Additionally, prior work demonstrating individual CNTs breaking at $300 \mathrm{nN}$ due to vertical tensile loading ${ }^{116}$ supports the argument that even at long $t_{\mathrm{p}}$, CNT failure within the nanotube is likely not the main mechanism governing $\sigma_{\mathrm{a}-\mathrm{s}}$, since $F_{\mathrm{f}-\mathrm{s}}$ only reaches up to $\sim 12 \mathrm{nN}$ at the longest $t_{\mathrm{p}}$. Therefore, it is reasonable that CNT array-substrate separation is attributed to $\mathrm{C}-\mathrm{C}$ layer cleavage at the $\mathrm{CNT}$ base. Since $\sigma_{\mathrm{a}-\mathrm{s}}$ values shown in Fig. 4a $(\sim 40-285 \mathrm{kPa})$ are of the same magnitude as $\sigma_{\mathrm{a}-\mathrm{s}}$ previously reported to range from tens to hundreds of $\mathrm{kPa}$ for similar CNT array areas, $E$, and $n,^{29,32,76}$ prior systems may also be described via this theoretical framework to enable tunable substrate adhesion.

Finally, the utility of this model to describe and accurately predict the substrate adhesion of other CNT arrays is demonstrated by the experimental-modeling agreement in Fig. $2 \mathrm{~b}$ and c, and by applying this framework to the exemplary CNT arrays in ref. 28 , where agreement between their $F_{\mathrm{f}-\mathrm{s}} \approx 12 \mathrm{nN}$ per CNT and $\sigma_{\mathrm{a}-\mathrm{s}} \approx 6.1 \mathrm{MPa}$ is achieved when eqn (1) and (2) are used with their reported $R_{\mathrm{o}}=5.5 \mathrm{~nm}, R_{\mathrm{i}}=3.6 \mathrm{~nm}, n=5 \times 10^{10}$ CNTs $\mathrm{cm}^{-2}, \gamma \approx 4.1 \mathrm{~J} \mathrm{~m}^{-2}$ (signifying the suggested Fe-alumina separating interface), ${ }^{19,82} \beta=1$ (assuming ideal CNT-substrate contact due to the early stage of growth and small array size), and $E \approx 20$ $\mathrm{MPa}$, which was not reported but is assumed to be reasonable due to their higher $n$ compared to our system, which can yield a greater number of inter-CNT connections to reinforce the array. $^{28,42}$ The ability of this model to accurately reflect the breaking Fe-alumina interface that was proposed in ref. 28, and its agreement with the previously reported NF-substrate adhesion values plotted in Fig. 2, show that this model may be extensible to different NF arrays given that the appropriate parameters are known or can be estimated. This work thereby offers an experimental-theoretical framework that may be broadly applied and supports the general trends in the literature, which report an increased adhesion strength with the surface energy and total VDW interaction energy ${ }^{51,79}$ attributed to increases in NF diameter, ${ }^{79,101,117}$ chemical and structural evolution at the adhesive interface, ${ }^{54,56}$ and contact area. ${ }^{59}$

\section{Conclusions}

In this work, we present experimental evidence and modelinformed mechanistic insight for the non-monotonic substrate adhesion evolution for aligned carbon nanotube (CNT) arrays, an exemplary nanofiber (NF) array system. We experimentally quantify the CNT array-substrate adhesion strength $\left(\sigma_{\mathrm{a}-\mathrm{s}}\right)$ for CNT process times $\left(t_{\mathrm{p}}\right)$ ranging from 9-80 min for mm-tall, cm-wide CNT arrays via uniform tensile CNT array separation from a flat growth substrate. Here, $\sigma_{\mathrm{a}-\mathrm{s}}\left(t_{\mathrm{p}}\right)$ is modeled via contact mechanics to better understand and predict CNT-substrate adhesion during CVD processing. We report that the evolution of $\sigma_{\mathrm{a}-\mathrm{s}}$ with $t_{\mathrm{p}}$ is driven by the bimodal scaling of CNT geometry, number density $(n)$, effective elastic array modulus $(E)$, and $\mathrm{C}-\mathrm{C}$ interfacial work of adhesion $(\gamma)$ during two regimes, termed Mode I ('Growth') and Mode II ('Post-Growth') separated by growth termination. Between Mode I and Mode II, experiments and modeling indicate an order-of-magnitude increase in $\sigma_{\mathrm{a}-\mathrm{s}}(\sim 40 \rightarrow 285 \mathrm{kPa})$ and $E$ $(\sim 6 \rightarrow 47 \mathrm{MPa})$, a two-orders-of-magnitude increase in the adhesion force per CNT $(\sim 0.190 \rightarrow 12.3 \mathrm{nN})$ and $\gamma(\sim 0.07 \rightarrow 1.5$ $\left.\mathrm{J} \mathrm{m}^{-2}\right)$, and an order-of-magnitude decrease in $n(\sim 2.10 \times$ $10^{10} \rightarrow 2.3 \times 10^{9}$ CNTs per $\mathrm{cm}^{2}$ ).

In this work, the observed increase in CNT wall thickness and $\mathrm{sp}^{3}$ bond character with $t_{\mathrm{p}}$ shows that the accumulation of carbon species in the CNT array strongly affects the mechanical response, which may be indicative of a change in deformation mechanism, i.e. a shift in the dominating carbon elastic constant from $\mathrm{C}_{44}$ to $\mathrm{C}_{33}$. These results indicate that the CNTs are not breaking in tension, as experiments and modeling show that the CNT roots separate from their carboncovered Fe catalyst particles at a $\mathrm{C}-\mathrm{C}$ interface during tensile pull-off, leaving the Fe particles completely on the substrate in each mode. Finally, the utility of this model to accurately describe the substrate adhesion of previously synthesized aligned NF arrays is demonstrated, establishing a theoretical framework to help inform process design and enhance NFsubstrate adhesion tunability for a wide range of commercial applications. In the future, additional characterization via in situ high-resolution SEM imaging during pull-off tests, TEM imaging of the CNT-substrate interfaces with $t_{\mathrm{p}}$, and in situ $\mathrm{X}$-ray analysis of the CNT-catalyst evolution during CNT nucleation at short $t_{\mathrm{p}}$, steady growth, growth termination, and extended $t_{\mathrm{p}}$ values would help to elucidate catalytic phase transformations, diffusion, and the structural evolution of the CNT-substrate interface. Using this approach, these results could enable versatile NF-substrate adhesion for better control over NF post-processing techniques, such as capillary densification, the spinning of NF yarns from forests, and post-growth $\mathrm{NF}$ array transfer for composite reinforcement, as well as for the design of high-value applications such as thermal interface materials, sensors, interconnects, field emitters, and dry adhesives, where interfacial bonding and morphology are critical for application-specific performance.

\section{Methods}

\section{Carbon nanotube growth via chemical vapor deposition}

Vertically aligned multiwall CNT arrays were grown by a basegrowth mechanism in a $22 \mathrm{~mm}$ internal diameter quartz tube 
furnace at atmospheric pressure via a previously described thermal catalytic CVD process using ethylene as the carbon source and $600 \mathrm{ppm}$ of water vapor added to inert helium gas. $^{73,118}$ The CNTs were grown on a catalytic layer composed of $1 \mathrm{~nm}$ Fe on $10 \mathrm{~nm} \mathrm{Al}_{2} \mathrm{O}_{3}$ deposited via electron beam physical vapor deposition on $1 \mathrm{~cm} \times 1 \mathrm{~cm} \mathrm{SiO}_{2} / \mathrm{Si}$ substrates. ${ }^{27}$ The growing CNTs self-assembled into aligned arrays of $h$ up to $\sim 4.7 \mathrm{~mm}$ for $t_{\mathrm{p}}$ from $9-80 \mathrm{~min}$, where $t_{\mathrm{p}}$ is the CNT process time (i.e. duration of ethylene gas flow during the CVD growth process). For this range of $t_{\mathrm{p}}$, the vertical arrays were comprised of multiwalled CNTs with an average outer diameter of 8-18 nm (3-16 walls with $~ 6 \mathrm{~nm}$ inner diameter and intrinsic CNT density of $\left.\approx 1.6 \mathrm{~g} \mathrm{~cm}^{-3}\right),{ }^{119}$ and an inter-CNT spacing of $\sim 60-80 \mathrm{~nm}^{75}$ and CNT volume fraction of $\sim 1 \%{ }^{73-75}$ (for a nominal $\sim 10$ min growth period yielding $1 \mathrm{~mm}$-tall CNTs). A minimum of four samples were grown for each $t_{\mathrm{p}}$, and the resulting CNT array heights $(h)$ were measured via optical microscopy using a Carl Zeiss Axiotech 30 HD optical microscope. $^{76}$

\section{Carbon nanotube-substrate adhesion testing}

To measure the normal CNT array-substrate adhesion force $\left(F_{\mathrm{a}-\mathrm{s}}\right)$ via vertical CNT array-substrate separation/pull-off, aluminum SEM stubs with silver epoxy were used to mount the CNT-substrate samples in the grips of a Zwick Roell mechanical tester operating in the tensile testing configuration, following the procedure first reported in ref. 76. A $\sim 1 \mathrm{~mm}$-thick layer of a viscous two-part silver epoxy was applied to the face of an SEM stub, on top of which a CNT array-Si wafer sample was placed (wafer side contacting epoxy) and cured for $4 \mathrm{~h}$ at room temperature. The stub was inserted into the lower grip of the mechanical tester. Then, a $\sim 1 \mathrm{~mm}-$ thick layer of epoxy was applied to the face of a second SEM stub, which was inserted into the upper grip and lowered until it contacted and covered the top of the CNT array, experiencing a load of $\sim 0.1 \mathrm{~N}$. The load returned to zero as the epoxy relaxed $<30$ microns into the stub-CNT interface, after which it was cured. $\sim 4-5$ samples for each $t_{\mathrm{p}}$ were then tested following ASTM D5179-02 (crosshead speed of $5 \mathrm{~cm} \mathrm{~min}^{-1}$, $500 \mathrm{~N}$ load cell), recording the load and displacement until the CNT array-Si wafer interfaces were ultimately separated. See section $\mathrm{S} 2$ in the $\mathrm{ESI} \dagger$ for additional details.

\section{CNT morphology characterization via electron microscopy}

SEM was performed using a Zeiss Merlin High-resolution SEM with an acceleration voltage of $1 \mathrm{kV}$ and an InLens detector. TEM samples were prepared via the ultrasonication of CNT array sections in isopropyl alcohol for five minutes. These CNTs were then dropcast onto a copper TEM grid, and the solvent was evaporated. The sample preparation of the TEM specimens was not limited to a specific location in the CNT array, and so the measured CNT wall thickness $(a)$ values represent an average throughout the array for each $t_{\mathrm{p}}{ }^{76}$ The TEM analysis was performed using a JEOL 2100 TEM at an acceleration voltage of $200 \mathrm{kV}$.

\section{Conflicts of interest}

There are no conflicts to declare.

\section{Acknowledgements}

This work was partially supported by Airbus, Boeing, ANSYS, Embraer, Lockheed Martin, Saab AB, Saertex, and Teijin Carbon America through MIT's Nano-Engineered Composite aerospace STructures (NECST) Consortium, the U. S. Army Research Office through the Institute for Soldier Nanotechnologies at MIT, under Contract Number W911NF13-D-0001 and W911NF-07-D-0004, and the National Aeronautics and Space Administration (NASA) Space Technology Research Institute (STRI) for Ultra-Strong Composites by Computational Design (US-COMP), grant number NNX17AJ32G. This work was performed in part at: the MIT MRSEC Shared Experimental Facilities supported by the National Science Foundation under award number DMR-0819762, facilities supported by the U. S. Army Research Office through the Institute for Soldier Nanotechnologies at MIT, under Collaborative Agreement Number W911NF-18-2-0048, and in part through the use of MIT's Microsystems Technology Laboratories and the Center for Nanoscale Systems (CNS) at Harvard University, a member of the National Nanotechnology Infrastructure Network (NNIN), which is supported by the National Science Foundation under award no. ECS-0335765. A. Kaiser was supported by the Department of Defense through the National Defense Science and Engineering Graduate Fellowship (NDSEG) Program. At MIT, the authors thank the members of necstlab for technical support and advice, and Prof. C. Thompson and Prof. M. Cima for helpful discussions.

\section{References}

1 R. Rao, C. L. Pint, A. E. Islam, R. S. Weatherup, S. Hofmann, E. R. Meshot, F. Wu, C. Zhou, N. Dee, P. B. Amama, J. Carpena-Nunez, W. Shi, D. L. Plata, E. S. Penev, B. I. Yakobson, P. B. Balbuena, C. Bichara, D. N. Futaba, S. Noda, H. Shin, K. S. Kim, B. Simard, F. Mirri, M. Pasquali, F. Fornasiero, E. I. Kauppinen, M. Arnold, B. A. Cola, P. Nikolaev, S. Arepalli, H.-M. Cheng, D. N. Zakharov, E. A. Stach, J. Zhang, F. Wei, M. Terrones, D. B. Geohegan, B. Maruyama, S. Maruyama, Y. Li, W. W. Adams and A. J. Hart, ACS Nano, 2018, 12, 11756-11784.

2 W. Wu, Nanoscale, 2017, 9, 7342-7372.

3 K. Kenry and C. T. Lim, Prog. Polym. Sci., 2017, 70, 1-17.

4 H. Sun, Y. Zhang, J. Zhang, X. Sun and H. Peng, Nat. Rev. Mater., 2017, 2, 17023.

5 M. M. Shulaker, G. Hills, R. S. Park, R. T. Howe, K. Saraswat, H.-S. P. Wong and S. Mitra, Nature, 2017, 547, 74. 
6 D. Zhong, Z. Zhang, L. Ding, J. Han, M. Xiao, J. Si, L. Xu, C. Qiu and L.-M. Peng, Nat. Electron., 2018, 1, 40-45.

7 M. F. L. De Volder, S. H. Tawfick, R. H. Baughman and A. J. Hart, Science, 2013, 339, 535-539.

8 J. Di, X. Wang, Y. Xing, Y. Zhang, X. Zhang, W. Lu, Q. Li and Y. T. Zhu, Small, 2014, 10, 4606-4625.

9 Y. Bai, R. Zhang, X. Ye, Z. Zhu, H. Xie, B. Shen, D. Cai, B. Liu, C. Zhang, Z. Jia, S. Zhang, X. Li and F. Wei, Nat. Nanotechnol., 2018, 13, 589-595.

10 L. Zhang, G. Zhang, C. Liu and S. Fan, Nano Lett., 2012, 12, 4848-4852.

11 S. J. Kim, S. A. Park, Y.-C. Kim and B.-K. Ju, J. Vac. Sci. Technol., B: Nanotechnol. Microelectron.: Mater., Process., Meas., Phenom., 2017, 35, 011802.

12 S. H. Tawfick, J. Bico and S. Barcelo, MRS Bull., 2016, 41, 108-114.

13 I. Lahiri, D. Lahiri, S. Jin, A. Agarwal and W. Choi, ACS Nano, 2011, 5, 780-787.

14 A. C. Ferrari, F. Bonaccorso, V. Fal'ko, K. S. Novoselov, S. Roche, P. Bøggild, S. Borini, F. H. L. Koppens, V. Palermo, N. Pugno, J. A. Garrido, R. Sordan, A. Bianco, L. Ballerini, M. Prato, E. Lidorikis, J. Kivioja, C. Marinelli, T. Ryhanen, A. Morpurgo, J. N. Coleman, V. Nicolosi, L. Colombo, A. Fert, M. Garcia-Hernandez, A. Bachtold, G. F. Schneider, F. Guinea, C. Dekker, M. Barbone, Z. Sun, C. Galiotis, A. N. Grigorenko, G. Konstantatos, A. Kis, M. Katsnelson, L. Vandersypen, A. Loiseau, V. Morandi, D. Neumaier, E. Treossi, V. Pellegrini, M. Polini, A. Tredicucci, G. M. Williams, B. Hee Hong, J.-H. Ahn, J. Min Kim, H. Zirath, B. J. van Wees, H. van der Zant, L. Occhipinti, A. Di Matteo, I. A. Kinloch, T. Seyller, E. Quesnel, X. Feng, K. Teo, N. Rupesinghe, P. Hakonen, S. R. T. Neil, Q. Tannock, T. Lofwander and J. Kinaret, Nanoscale, 2015, 7, 4598-4810.

15 Y. Zhang, E. Suhir, Y. Xu and C. Gu, J. Mater. Res., 2006, 21, 2922-2926.

16 B. Chen, G. Zhong, P. Goldberg Oppenheimer, C. Zhang, H. Tornatzky, S. Esconjauregui, S. Hofmann and J. Robertson, ACS Appl. Mater. Interfaces, 2015, 7, 3626-3632.

17 B. Hu, H. Ago, N. Yoshihara and M. Tsuji, J. Phys. Chem. C, 2010, 114, 3850-3856.

18 C. L. Pint, Y.-Q. Xu, S. Moghazy, T. Cherukuri, N. T. Alvarez, E. H. Haroz, S. Mahzooni, S. K. Doorn, J. Kono, M. Pasquali and R. H. Hauge, ACS Nano, 2010, 4, 1131-1145.

19 L. Ping, P.-X. Hou, H. Wang, M. Chen, Y. Zhao, H. Cong, C. Liu and H.-M. Cheng, Carbon, 2018, 133, 275-282.

20 Y. Hwang, S. Yoo, N. Lim, S. M. Kang, H. Yoo, J. Kim, Y. Hyun, G. Y. Jung and H. C. Ko, ACS Nano, 2020, 14, 118-128.

21 J. Ni and Y. Li, Adv. Energy Mater., 2016, 6, 1600278.

22 L. Mai, X. Tian, X. Xu, L. Chang and L. Xu, Chem. Rev., 2014, 114, 11828-11862.

23 Y. Zhang, Y.-J. Heo, Y.-R. Son, I. In, K.-H. An, B.-J. Kim and S.-J. Park, Carbon, 2019, 142, 445-460.
24 E. S. Avraham, A. S. Westover, A. Itzhak, L. Shani, V. Mor, O. Girshevitz, C. L. Pint and G. D. Nessim, Carbon, 2018, 130, 273-280.

25 E. R. Meshot, M. Bedewy, K. M. Lyons, A. R. Woll, K. A. Juggernauth, S. Tawfick and A. J. Hart, Nanoscale, 2010, 2, 896-900.

26 R. Guzman de Villoria, A. J. Hart and B. L. Wardle, ACS Nano, 2011, 5, 4850-4857.

27 A. L. Kaiser, I. Y. Stein, K. Cui and B. L. Wardle, Phys. Chem. Chem. Phys., 2018, 20, 3876-3881.

28 J. Brown, T. Hajilounezhad, N. T. Dee, S. Kim, A. J. Hart and M. R. Maschmann, ACS Appl. Mater. Interfaces, 2019, 38(11), 35221-35227.

29 P. Pour Shahid Saeed Abadi, S. B. Hutchens, J. R. Greer, B. A. Cola and S. Graham, Appl. Phys. Lett., 2013, 102, 223103.

30 Y. Gao, T. Kodama, Y. Won, S. Dogbe, L. Pan and K. E. Goodson, Carbon, 2012, 50, 3789-3798.

31 A. J. Hart and A. H. Slocum, Nano Lett., 2006, 6, 12541260.

32 P. Pour Shahid Saeed Abadi, S. B. Hutchens, J. R. Greer, B. A. Cola and S. Graham, Nanoscale, 2012, 4, 3373-3380.

33 J. Choi, Y. Eun and J. Kim, ACS Appl. Mater. Interfaces, 2014, 6, 6598-6605.

34 B. Chen, M. Gao, J. M. Zuo, S. Qu, B. Liu and Y. Huang, Appl. Phys. Lett., 2003, 83, 3570-3571.

35 B. Bhushan, X. Ling, A. Jungen and C. Hierold, Phys. Rev. B: Condens. Matter Mater. Phys., 2008, 77, 165428.

36 B. Bhushan and X. Ling, Phys. Rev. B: Condens. Matter Mater. Phys., 2008, 78, 045429.

37 C. Ke, M. Zheng, G. Zhou, W. Cui, N. Pugno and R. N. Miles, Small, 2010, 6, 438-445.

38 A. Cao, V. P. Veedu, X. Li, Z. Yao, M. N. Ghasemi-Nejhad and P. M. Ajayan, Nat. Mater., 2005, 4, 540.

39 M. Stadermann, S. P. Sherlock, J.-B. In, F. Fornasiero, H. G. Park, A. B. Artyukhin, Y. Wang, J. J. De Yoreo, C. P. Grigoropoulos, O. Bakajin, A. A. Chernov and A. Noy, Nano Lett., 2009, 9, 738-744.

40 M. Bedewy, E. R. Meshot, H. Guo, E. A. Verploegen, W. Lu and A. J. Hart, J. Phys. Chem. C, 2009, 113, 20576-20582.

41 X. Cui, W. Wei, C. Harrower and W. Chen, Carbon, 2009, 47, 3441-3451.

42 I. Y. Stein, D. J. Lewis and B. L. Wardle, Nanoscale, 2015, 7, 19426-19431.

43 S. Cranford, H. Yao, C. Ortiz and M. J. Buehler, J. Mech. Phys. Solids, 2010, 58, 409-427.

44 M. R. Maschmann, Carbon, 2015, 86, 26-37.

45 Y. Won, Y. Gao, M. A. Panzer, R. Xiang, S. Maruyama, T. W. Kenny, W. Cai and K. E. Goodson, Proc. Natl. Acad. Sci. U. S. A., 2013, 110, 20426-20430.

46 H. Cebeci, I. Y. Stein and B. L. Wardle, Appl. Phys. Lett., 2014, 104, 023117.

47 V. L. Popov, R. Pohrt and Q. Li, Friction, 2017, 5, 308-325.

48 V. Popov, M. Heß and E. Willert, Handbook of Contact Mechanics: Exact Solutions of Axisymmetric Contact Problems, Springer Berlin Heidelberg, 2019. 
49 D. Tabor, J. Colloid Interface Sci., 1977, 58, 2-13.

50 K. Kendall, J. Phys. D: Appl. Phys., 1971, 4, 1186.

51 R. S. Ruoff, J. Tersoff, D. C. Lorents, S. Subramoney and B. Chan, Nature, 1993, 364, 514-516.

52 R. Spolenak, G. Stanislav, G. Huajian and A. Eduard, Proc. R. Soc. A, 2005, 461, 305-319.

53 H. Gao, X. Wang, H. Yao, S. Gorb and E. Arzt, Mech. Mater., 2005, 37, 275-285.

54 M. R. Roenbeck, X. Wei, A. M. Beese, M. Naraghi, A. Furmanchuk, J. T. Paci, G. C. Schatz and H. D. Espinosa, ACS Nano, 2014, 8, 124-138.

55 C. T. Wirth, S. Hofmann and J. Robertson, Diamond Relat. Mater., 2008, 17, 1518-1524.

56 M. R. Roenbeck, A. Furmanchuk, Z. An, J. T. Paci, X. Wei, S. T. Nguyen, G. C. Schatz and H. D. Espinosa, Nano Lett., 2015, 15, 4504-4516.

57 Y. Chen, D. Ding, C. Zhu, J. Zhao and T. Rabczuk, Compos. Struct., 2019, 208, 150-167.

58 M. R. Maschmann, Q. Zhang, R. Wheeler, F. Du, L. Dai and J. Baur, ACS Appl. Mater. Interfaces, 2011, 3, 648-653.

59 L. Qu, L. Dai, M. Stone, Z. Xia and Z. L. Wang, Science, 2008, 322, 238-242.

60 B. Aksak, M. P. Murphy and M. Sitti, IEEE International Conference on Robotics and Automation, 2008, pp. 3058-3063.

61 D. Sameoto and C. Menon, J. Micromech. Microeng., 2009, 19, 115002 .

62 Y. Tian, N. Pesika, H. Zeng, K. Rosenberg, B. Zhao, P. McGuiggan, K. Autumn and J. Israelachvili, Proc. Natl. Acad. Sci. U. S. A., 2006, 103, 19320-19325.

63 Y. P. Zhao, L. S. Wang and T. X. Yu, J. Adhes. Sci. Technol., 2003, 17, 519-546.

64 V. Tinnemann, L. Hernandez, S. C. L. Fischer, E. Arzt, R. Bennewitz and R. Hensel, Adv. Funct. Mater., 2019, 29, 1807713.

65 M. Bedewy, E. R. Meshot and A. J. Hart, Carbon, 2012, 50, 5106-5116.

66 Y. Zhao, T. Tong, L. Delzeit, A. Kashani, M. Meyyappan and A. Majumdar, J. Vac. Sci. Technol., B: Microelectron. Nanometer Struct.-Process., Meas., Phenom., 2006, 24, 331-335.

67 X. Li, X. Zhang, L. Ci, R. Shah, C. Wolfe, S. Kar, S. Talapatra and P. M. Ajayan, Nanotechnology, 2008, 19, 455609.

68 S. Yasuda, T. Hiraoka, D. N. Futaba, T. Yamada, M. Yumura and K. Hata, Nano Lett., 2009, 9, 769-773.

69 S. Santangelo, M. Lanza and C. Milone, J. Phys. Chem. C, 2013, 117, 4815-4823.

70 V. Thiagarajan, X. Wang, P. Bradford, Y. Zhu and F. Yuan, Compos. Sci. Technol., 2014, 90, 82-87.

71 A. A. Puretzky, D. B. Geohegan, S. Jesse, I. N. Ivanov and G. Eres, Appl. Phys. A, 2005, 81, 223-240.

72 C. Singh, M. S. Shaffer and A. H. Windle, Carbon, 2003, 41, 359-368.

73 J. Lee, I. Y. Stein, M. E. Devoe, D. J. Lewis, N. Lachman, S. S. Kessler, S. T. Buschhorn and B. L. Wardle, Appl. Phys. Lett., 2015, 106, 053110.

74 I. Y. Stein and B. L. Wardle, Phys. Chem. Chem. Phys., 2016, 18, 694 .
75 I. Y. Stein and B. L. Wardle, Phys. Chem. Chem. Phys, 2013, 15, 4033-4040.

76 D. L. Lidston, M.Sc. thesis, Massachusetts Institute of Technology, 2017.

77 D. N. Futaba, K. Hata, T. Namai, T. Yamada, K. Mizuno, Y. Hayamizu, M. Yumura and S. Iijima, J. Phys. Chem. B, 2006, 110, 8035-8038.

78 L. Zhu, Y. Xiu, D. W. Hess and C.-P. Wong, Nano Lett., 2005, 5, 2641-2645.

79 J.-H. Han, R. A. Graff, B. Welch, C. P. Marsh, R. Franks and M. S. Strano, ACS Nano, 2008, 2, 53-60.

80 D.-M. Tang, C. Liu, W.-J. Yu, L.-L. Zhang, P.-X. Hou, J.-C. Li, F. Li, Y. Bando, D. Golberg and H.-M. Cheng, ACS Nano, 2014, 8, 292-301.

81 C. L. Pint, Y.-Q. Xu, M. Pasquali and R. H. Hauge, ACS Nano, 2008, 2, 1871-1878.

82 C. Mattevi, C. T. Wirth, S. Hofmann, R. Blume, M. Cantoro, C. Ducati, C. Cepek, A. Knop-Gericke, S. Milne, C. Castellarin-Cudia, S. Dolafi, A. Goldoni, R. Schloegl and J. Robertson, J. Phys. Chem. C, 2008, 112, 12207-12213.

83 M. Bedewy, E. R. Meshot, M. J. Reinker and A. J. Hart, ACS Nano, 2011, 5, 8974-8989.

84 X. Liang, J. Shin, D. Magagnosc, Y. Jiang, S. J. Park, A. J. Hart, K. Turner, D. S. Gianola and P. K. Purohit, Int. J. Solids Struct., 2017, 122-123, 196-209.

85 C.-C. Su, T.-X. Chen and S.-H. Chang, Materials, 2017, 10, 206.

86 J.-P. Salvetat, J.-M. Bonard, N. H. Thomson, A. J. Kulik, L. Forro, W. Benoit and L. Zuppiroli, Appl. Phys. A, 1999, 69, 255-260.

87 X. Lim, H. W. G. Foo, G. H. Chia and C.-H. Sow, ACS Nano, 2010, 4, 1067-1075.

88 A. L. Kaiser, I. Y. Stein, K. Cui and B. L. Wardle, Nano Futures, 2019, 3, 011003.

89 S. C. Roh, E. Y. Choi, Y. S. Choi and C. Kim, Polymer, 2014, 55, 1527-1536.

90 A. Zebda, H. Sabbah, S. Ababou-Girard, F. Solal and C. Godet, Appl. Surf. Sci., 2008, 254, 4980-4991.

91 X. Yuan, J. Yang, J. He, H. H. Tan and C. Jagadish, J. Phys. D: Appl. Phys., 2018, 51, 283002.

92 W. Li, Y. Li, M. Sheng, S. Cui, Z. Wang, X. Zhang, C. Yang, Z. Yu, Y. Zhang, S. Tian, Z. Dai and Q. Xu, Langmuir, 2019, 35, 4527-4533.

93 L. S. Kocherlakota, B. A. Krajina and R. M. Overney, J. Chem. Phys., 2015, 143, 241105.

94 R. J. Cartwright, S. Esconjauregui, R. S. Weatherup, D. Hardeman, Y. Guo, E. Wright, D. Oakes, S. Hofmann and J. Robertson, Carbon, 2014, 75, 327334.

95 M. Xia, C. Liang, Z. Cheng, R. Hu and S. Liu, Phys. Chem. Chem. Phys., 2019, 21, 1217-1223.

96 R. Zacharia, H. Ulbricht and T. Hertel, Phys. Rev. B: Condens. Matter Mater. Phys., 2004, 69, 155406.

97 M. S. Dresselhaus, A. Jorio, M. Hofmann, G. Dresselhaus and R. Saito, Nano Lett., 2010, 10, 751-758. 
98 A. C. Ferrari and J. Robertson, Phys. Rev. B: Condens. Matter Mater. Phys., 2000, 61, 14095-14107.

99 L. G. Cancado, A. Jorio, E. H. M. Ferreira, F. Stavale, C. A. Achete, R. B. Capaz, M. V. O. Moutinho, A. Lombardo, T. S. Kulmala and A. C. Ferrari, Nano Lett., 2011, 11, 3190-3196.

100 A. L. Kaiser, M.Sc. thesis, Massachusetts Institute of Technology, 2019.

101 X. Yuan and Y. Wang, J. Phys. D: Appl. Phys., 2017, 50, 395303.

102 M. De Volder, S. H. Tawfick, S. J. Park, D. Copic, Z. Zhao, W. Lu and A. J. Hart, Adv. Mater., 2010, 22, 4384-4389.

103 M. Bedewy, J. Mater. Res., 2017, 32, 153-165.

104 V. Balakrishnan, M. Bedewy, E. R. Meshot, S. W. Pattinson, E. S. Polsen, F. Laye, D. N. Zakharov, E. A. Stach and A. J. Hart, ACS Nano, 2016, 10, 11496-11504.

105 S. Jeong, J. Lee, H.-C. Kim, J. Y. Hwang, B.-C. Ku, D. N. Zakharov, B. Maruyama, E. A. Stach and S. M. Kim, Nanoscale, 2016, 8, 2055-2062.

106 M. He, Y. Magnin, H. Amara, H. Jiang, H. Cui, F. Fossard, A. Castan, E. Kauppinen, A. Loiseau and C. Bichara, Carbon, 2017, 113, 231-236.

107 C. Zhang, A. C. van Duin, J. W. Seo and D. Seveno, Carbon, 2017, 115, 589-599.

108 J.-Q. Huang, Q. Zhang, M.-Q. Zhao and F. Wei, Carbon, 2010, 48, 1441-1450.
109 D. Tromans and J. Meech, Miner. Eng., 2002, 15, 10271041.

110 A. Schron and F. Bechstedt, Phys. Rev. B: Condens. Matter Mater. Phys., 2015, 92, 165112.

111 S. Zhao, X.-W. Liu, C.-F. Huo, Y.-W. Li, J. Wang and H. Jiao, J. Catal., 2012, 294, 47-53.

112 H. Hugosson, O. Eriksson, U. Jansson, A. Ruban, P. Souvatzis and I. Abrikosov, Surf. Sci., 2004, 557, 243254.

113 G. Savini, Y. Dappe, S. Oberg, J.-C. Charlier, M. Katsnelson and A. Fasolino, Carbon, 2011, 49, 62-69.

114 G. Guhados, W. Wan, X. Sun and J. L. Hutter, J. Appl. Phys., 2007, 101, 033514.

115 N. Dee, M. Bedewy, A. Rao, J. Beroz, B. Lee, E. R. Meshot, C. A. Chazot, P. R. Kidambi, H. Zhao, T. Serbowicz, K. Teichert, P. K. Purohit and A. J. Hart, Chem. Mater., 2019, 31, 407-418.

116 K. Liew, C. Wong and M. Tan, Acta Mater., 2006, 54, 225231.

117 J. Liu, X. Tang, Y. Li, Z. Dai, F. Chen, H. Huang, H. Li, H. Liu and D. Chen, Mater. Chem. Phys., 2017, 196, 160169.

118 I. Y. Stein, A. L. Kaiser, A. J. Constable, L. Acauan and B. L. Wardle, J. Mater. Sci., 2017, 52, 13799-13811.

119 I. Y. Stein, N. Lachman, M. E. Devoe and B. L. Wardle, ACS Nano, 2014, 8, 4591-4599. 